\title{
A DERMATOLOGICAL SURVEY OF THE GURKHA BRIGADE
}

\author{
Lieutenant-Colonel A. G. JARRAMS \\ M.B., Ch.B., M.R.C.G.P., D.T.M.\&H., D.D.M., R.A.M.C. \\ British Military Hospital, Rinteln
}

SUMMARY: A survey was carried out on 4,500 serving officers and soldiers of the Brigade of Gurkhas in Singapore, Malaya and Hong Kong in 1971 and 1972. The results showed a prevalence of $\mathbf{1 1 . 3}$ cases of leprosy per thousand in this highly selected group. It is suggested that some prevous estimates of the prevalence of leprosy in the general population of the Himalayan foothills underestimated the problem.

\section{Introduction}

The Ridley Jopling classification of leprosy (Ridley and Jopling 1966) is generally accepted as an immunological basis in clinical leprosy. Figure 1 summarizes the classification.

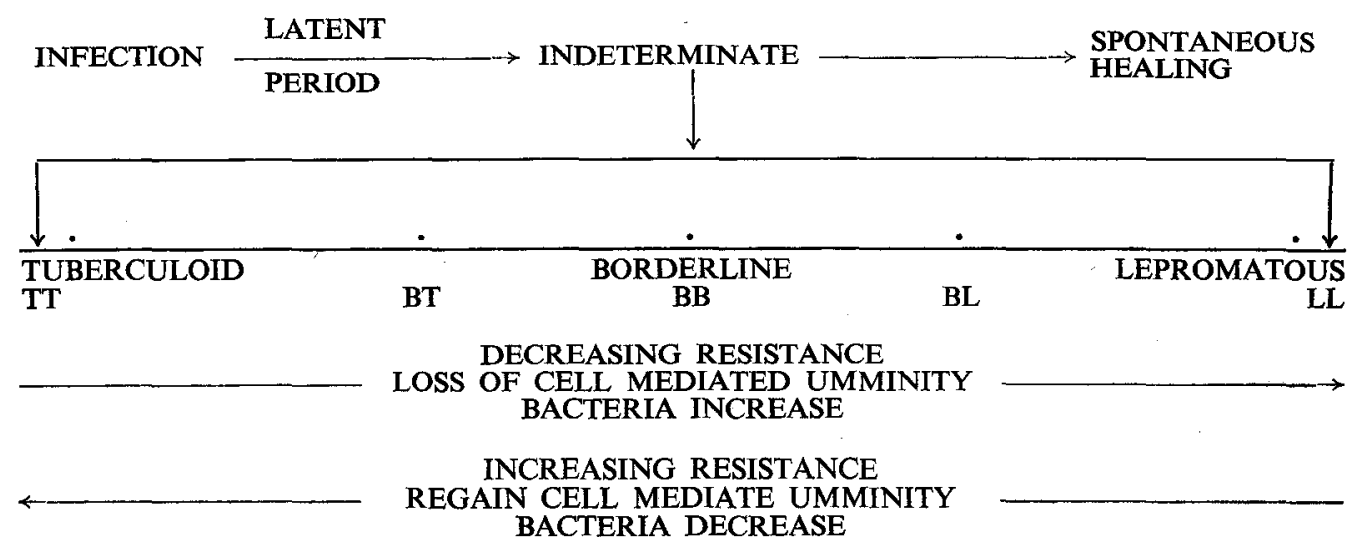

Fig. 1. Summary of the Ridley Jopling classification of leprosy

The prevalence of leprosy in the northern regions of the Indian sub-continent has been variously estimated from 1.15 to 39.3 per thousand (Hajini and Shah 1974, Nepal Health Survey 1966, Mali 1971, Berkeley and Berkeley 1969).

The difficulties of estimating the prevalence of leprosy are considerable, particularly in view of the persistence of superstitions and taboos, not only among sufferers but also officials in countries where the disease is endemic or hyperendemic.

In a recent paper (Browne 1973) stated:

"The actual prevalence of leprosy in the community varies within wide limits". "Since no specific tests of skin sensitivity (indicating past or present infection) or of serological diagnosis exist, complete prevalence rates dependent on accurate clinical diagnosis of leprosy are lacking, and mass screening is not generally possible. Visible abnormalities of the skin are as difficult to differentiate as vague radioscopic changes in the lung fields in tuberculosis". 
The Gurkha Brigade, with 27 known cases of leprosy, it was felt, should be surveyed to obtain an accurate prevalence rate. This was possible, of course, because of the comparatively small numbers of the 'captive' population, which was well motivated to the investigation.

\section{Materials and methods}

The survey was carried out on 4,498 Nepalis serving in the Gurkha Brigade of the British Army while the author. was Dermatologist to the British Services in Singapore, Malaya and'Hong Kong.

It was not possible to examine all the members of the Brigade owing to the absence of some on long leave in Nepal and on extra-regimental employment in other areas. With the willing co-operation of officers, non-commissioned officers and regimental medical officers, it was possible to examine about 300 men in one day and to document the observations.

The examination was held in a large room. The examiner stood with his back to a window, facing him a chair was placed with a screen round three sides blocking off the changing area beyond. To the examiner's left soap, towels and water were placed for his use, whilst to his right and in line with one side of the screen a table was placed for the company clerk. The Gurkhas then filed past one at a time between the left of the screen and the company clerk, sat in the chair for examination then dispersed to their right back to the changing area.

The company clerk collected the prepared slips, on which the number, rank and name of the man was written, and then recorded the examiner's observations by agreed abbreviations (for example, PV-Pityriasis versicolor. R-review by examiner. RMO -review by regimental medical officer). There were 26 agreed abbreviations and any additional observations were written longhand by the examiner.

Each subject presented for examination dressed only in PT shorts and 'flip-flops' a form of dress easily adopted in Singapore and the Hong Kong summer but less so in the Hong Kong winter. The man stood while the mouth, head and neck were examined, particular note being made of mouth ulceration, cervical lymphadenopathy and enlargement of the great auricular nerves.

The ulnar nerves at the elbows and radial nerves at the wrists were palpated while the upper trunk and arms were scanned for any lesions. Epitrochlear and axillary lymphadenopathy were sought and the soldier then removed his shorts. The genitalia were examined for active lesions, scarring and local inguinal lymphadenopathy, hernia etc. The buttocks, perianal region, perineum and backs of legs were inspected prior to the subject sitting for palpation of the lateral popliteal nerves and scrutiny of the soles and toe clefts. This procedure for each man occupied about one minute.

\section{Results}

Table 1 shows the number of known leprosy patients prior to the survey and the total on completion. The inclusion of a 'not known' is unavoidable because of some records not being available due to hospital closures, leave in Nepal etc.

The distribution of the lesions was as one would expect, with single indeterminate and tuberculoid lesions occurring anywhere on the body and the more numerous lepro- 
matous lesions being widespread and symmetrical. No patients with only neural lesions were seen although two were reviewed with widespread possible nerve enlargement. A further 28 men were referred to the Unit Medical Officer for observation with lesions suggestive of indeterminate leprosy.

Table II shows the skin conditions commonly observed in the survey. Not all of these conditions were referred for treatment or observation but some of the extensive pityriasis versicolor required treatment before it could be confidently decided that no other abnormality was present.

Table I

Number of known leprosy patients prior to and on completion of the survey

\begin{tabular}{l|c|c|c}
\hline & Pre survey & Survey & Total \\
\hline Indeterminate & 2 & 7 & 9 \\
\hline Tuberculoid & 6 & 14 & 20 \\
\hline Borderline tuberculoid & 2 & - & 2 \\
\hline Borderline lepromatous & 6 & 3 & 9 \\
\hline Lepromatous & 5 & 1 & 6 \\
\hline Not known & 6 & - & 6 \\
\hline Totals & 27 & 25 & 52 \\
\hline
\end{tabular}

Table II

Number of skin conditions commonly observed in the survey

\begin{tabular}{l|c|c|c}
\hline & Number & Percentage & Range in groups \\
\hline Pityriasis versicolor & 784 & 17.4 & $8.6: 34.8$ \\
\hline Warts & 326 & 7.2 & $5.4: 9.6$ \\
\hline Tinea pedis & 1307 & 29.1 & $8.4: 35.5$ \\
\hline Tinea cruris & 81 & 1.8 & $1.0: 2.8$ \\
\hline Acne & 855 & 19.0 & $8.1: 38.5$ \\
\hline Naevus linear verrucose & 68 & 1.5 & $0: 2.1$ \\
\hline Naevus anaemic & 104 & 2.3 & $0.1: 4.3$ \\
\hline Accesory nipples & 322 & 7.2 & - \\
\hline Tattoo & 392 & 8.7 & $2.4: 18.7$ \\
\hline Keloid & 139 & 3.1 & $1.1: 4.6$ \\
\hline Eezema (all types) & 76 & 1.7 & - \\
\hline
\end{tabular}

The diagnosis of tinea pedis was made on clinical grounds only when there was strong evidence i.e. interdigital maceration and fissuring. Lesions not in the clefts were 
reviewed for scrapings before treatment was prescribed. The smallest percentage of cases of tinea pedis was seen in the cooler weather of Honk Kong winter and the highest in the battalion recently returned from two months arduous training in the jungle. Tinea cruris was seen rather less than expected ( 1.8 per cent) presumably due to the common practice amongst the younger soldiers of wearing swimming trunks as underpants and wide-legged shorts thus reducing apposition of skin surfaces and increasing air circulation.

Acne was cystic and pustular in only 46 of the total 855 cases, which were of the superficial papulo-pustular type and was also more evident in a battalion returning from duty in Borneo. The lowest percentage being associated again with the Hong Kong winter.

Warts showed no significant variation with climate but the distribution tended to be more widespread on the lower limbs than usually observed in Caucasians. Single naevi were not recorded as this would have been a monumental undertaking but the linear verrucose naevus ( 1.5 per cent) is distinctive as is also the anaemic naevus ( 2.3 per cent) and were recorded for comparison with any future studies. Accessory nipples were noted in 7.2 per cent. bilateral in 28 per cent of the total of 322 .

The tattooes were interesting, in that they were almost all forearm designs mostly black and usually distinctive to the place of acquisition, which the examiner could, later in the survey, confidently identify, for example, Katmandu, Benares, Calcutta. Occasionally the multicoloured artistry of a more sophisticated practitioner from Hong Kong was seen. Of the total of 392 , only a surprisingly small number 20 ( 5 per cent) were self inflicted amateur designs consisting of copies of the Hindu Goddess, place names, one blood group and one the subject's last four numbers, by which the Gurkha soldiers are known rather than by name. Few had the elegant and none the obscene designs of the white British servicemen illustrated by Scutt and Gotch (1974), who also record a tattoo incidence of 46.2 per cent in 2,000 naval personnel compared to the 8.7 per cent in this survey.

There are no figures to compare the 3.1 per cent keloid scarring with other ethnic groups but the lesions in the Gurkhas tended to be mostly small and papular rather than the large plaques seen in negroid patients.

Table III shows the various lesions discovered coincidentally during the survey.

The total number in each group does not generally warrant recording as a percentage or pro mille. The occurrence of penile vitiligo, four times as often as more widespread vitiligo, with no evidence of its being post inflammatory hypopigmentation or contact eczema, cannot be explained.

The persistance of Mongoloid spots in eight subjects confirms that this does occur, albeit rarely, over the age of 15 years. Two cases of trigeminal capillary naevus were not associated with ocular or radiological abnormality of the meninges. Biopsies were not made on patients with lesions which were symptomless and considered to be harmless, for example, the penile lesions of lichen nitidus.

The sexually transmitted diseases were dealt with as indicated at the time, usually referral to the venereology department (S.T.C.), British Military Hospital, Hong Kong where some of the patients had been or were still under treatment and surveillance. None of those subsequently diagnosed as suffering from lymphogranuloma venereum 
Table III

Number of lesions discovered coincidentally during the survey

\begin{tabular}{l|r|l|l|l|l}
\hline \multicolumn{5}{c}{ Skin } \\
\hline Vitiligo general & 7 & Naevi ' Becker & \multicolumn{3}{l}{} \\
Vitiligo penile & 26 & Naevi capillary & 2 & Keratosis pilaris & 3 \\
Mongloid spots & 8 & Naevi trigeminal angiomatous & 3 & Epidermoid cysts & 1 \\
Lichen nitidus & 11 & Halo naevi & 8 & Gherry angiomata & 1 \\
Lichen aureus & 1 & Sebocystomatosis scrotal & 1 & Papilloma annulare & 1 \\
Lichen amyloid & 1 & Urticaria pigmentosa & 1 & Xanthelasma & 1 \\
Ichthyosis & 2 & Overcurvature of nails & 2 & Syringomata & 1 \\
Urticaria & 10 & Hemihypertrophy of tongue & 1 & Ulcer tongue & 1 \\
Miliaria & 1 & Hidradenitis suppurativa & 4 & Spider naevi & 2 \\
Leukonychia & 1 & Lymphangioma circumscriptum & 1 & Trichoepithelioma & 1 \\
Pruritis ani & 2 & Geographical tongue & 2 & Accessory auricle & 6 \\
\hline
\end{tabular}

Veneral disease

\begin{tabular}{|c|c|c|c|c|c|c|c|}
\hline \multicolumn{2}{|c|}{$\begin{array}{l}\text { Lymphogranuloma venereum } \\
\text { Primary syphilis ( } 3 \text { under treatment) } \\
\text { Chancroid } \\
\text { Non specific urethritis } \\
\text { Gonorrhoea }\end{array}$} & $\begin{array}{r}13 \\
10 \\
4 \\
1 \\
1\end{array}$ & \multicolumn{4}{|c|}{$\begin{array}{l}\text { Balanoposthitis } \\
\text { Lymphadenopathy- } \\
\text { Local } \\
\text { Generalised }\end{array}$} & $\begin{array}{r}16 \\
2\end{array}$ \\
\hline \multicolumn{2}{|l|}{ Medical } & \multicolumn{4}{|c|}{ Infections } & \multicolumn{2}{|c|}{ Infestations } \\
\hline $\begin{array}{l}\text { Jaundice (virus hepatitis) } \\
\text { Mumps } \\
\text { Chicken pox } \\
\text { Tophus } \\
\text { Zoster }\end{array}$ & $\begin{array}{l}1 \\
1 \\
1 \\
1 \\
2\end{array}$ & $\begin{array}{l}\text { Boils } \\
\text { Molluscum } \\
\text { Trichomyco } \\
\text { Impetigo } \\
\text { Tinea corpc } \\
\text { Chronic par }\end{array}$ & $\begin{array}{l}\text { ntagiosum } \\
\text { axillaris } \\
\text { aychia }\end{array}$ & & $\begin{array}{r}4 \\
20 \\
4 \\
1 \\
27 \\
1\end{array}$ & $\begin{array}{l}\text { Scabies } \\
\text { Cutaneous } \\
\text { Larva migrans } \\
\text { Phthiriasis } \\
\text { (crabs) }\end{array}$ & $\begin{array}{l}3 \\
3 \\
3\end{array}$ \\
\hline \multicolumn{8}{|c|}{ Surgical } \\
\hline $\begin{array}{l}\text { Varicose veins } \\
\text { Ingional hernia } \\
\text { Phimosis }\end{array}$ & $\begin{array}{r}42 \\
19 \\
8\end{array}$ & $\begin{array}{l}\text { Varicocele } \\
\text { Meatal cyst } \\
\text { Osgood Schla } \\
\text { disease } \\
\text { Epispadias }\end{array}$ & & $\begin{array}{l}6 \\
3\end{array}$ & & $\begin{array}{l}\text { naecomastia } \\
\text { omata } \\
\text { puytrens } \\
\text { ontracture }\end{array}$ & $\begin{array}{r}1 \\
13\end{array}$ \\
\hline
\end{tabular}

had presented either to the Unit medical officer or to the S.T.C. Lymphogranuloma complement-fixation tests in two cases gave positives at $1 / 1280$ while the remainder were of the order of $1 / 160$.

Neither systemic nor syphilitic disease became evident on investigation of those with inguinal lymphadenopathy in the absence of penile lesions but serological tests for syphilis were positive in two patients with generalised lymphadenopathy.

The general medical and surgical conditions are self explanatory and were referred to colleagues in the appropriate department for the expert opinion and treatment. Of the total number examined, 217 men ( 4.8 per cent) were referred for review by the Unit medical officer and 220 men ( 4.9 per cent) were reviewed by the author. 


\section{Discussion}

The problems of superstition and taboo referred to earlier are illustrated in the following passage quoted from Nepalese Law by Mali (1966):-

"A marriage will be declared null and void if the woman finds that her husband is suffering from any of the following complaints and she does not consent to continue the marriage relationship and the facts have been concealed by the go-between-Dumbness, leprosy etc. The deceiver (go-between) shall be fined Rs.500. Vice versa in the case of the husband.

A man shall not marry another woman so long as his wife is alive or had not been divorced legally except on the following conditions: $a$. If the wife had got leprosy. $b$. If the wife has got incurable disease of the genital tract. $c$. If the wife is incurably insane. $d$. If the couple is barren after ten years of marriage. $e$. If the wife is crippled and unable to walk. $f$. If the wife is blind in both eyes.

The local governor or the magistrate shall send leprosy patients to the place meant for them. A leprosy patient shall not be eligible for Village Panchayat (council) election."

Fortunately there is now a much more enlightened attitude but despite this law having been repealed, the patient remains in fear of losing his land, having to leave his village and live in an institution for the rest of his life, thus discouraging patients from presenting for diagnostic examination in case-finding surveys.

On completion of his service, a Gurkha soldier with leprosy may return to Nepal and continue treatment, collecting the supply of drugs at the same time as his pension.

The indeterminate and tuberculoid cases presented no difficulty managed in this way, although there could be no check as to whether the drugs were taken correctly. The lepromatous and borderline cases, however, could not be allowed to return to remote farms in Nepal, often 4 to 5 days walk from medical care, until they had passed the stage of possible reaction. Exceptions had to be made occasionally for compassionate reasons, when the patient was established on clofazimine prior to departure and a supply given to cover the period of absence from supervision.

All patients were given strict instructions as to the length of treatment required (indeterminate 3 years, tuberculoid 5 years, boderline 15 years, lepromatous at least 25 years) and while these times are longer than recommended by some leprologists it was felt better to err on too long a time rather than too short. It was furthermore stressed that regular treatment is essential and that tablets must not be distributed to friends and relatives.

As expected the survey revealed more patients with indeterminate and tuberculoid leprosy (21) than with borderline lepromatous and lepromatous disease (4). The totals show a lepromatous to non-lepromatous ratio of $1: 2$. Browne (1973) observed that this rate increases from 1:9 in Africa to 1:3 in India and 1:1 or 2 in Mongoloids. The leprosy patients reported here with ethnic overlap do not conform to this pattern but more with those reported below. Other surveys, as mentioned in the Introduction, give widely varying rates for Nepal and neighbouring countries.

Hajini and Shah (1974) in arriving at the low figure of 1.15 per thousand for Kashmir took the total number of leprosy patients (5329) and divided by the total population $(4,615,176)$. The lepromatous to non-lepromatous ratio was reported as $1: 2$. 
The Nepal Health Survey (1966) in its examination of 5011 persons assessed a prevalence rate of 1 per cent but the subjects were at best only partially disrobed and the number of definite cases discovered was nine a prevalence of 1.8 per thousand.

Mali (1969) in two surveys of 31,000 schoolchildren and 50,000 of the general population in Nepal found a prevalence rate of 8.6 and 2.1 per thousand respectively compared to 1.5 and 5.7 in his previous publication (Mali 1966), and 8 per thousand in schoolchildren in a later survey of an unspecified number (Mali 1971). The case detection was carried out by para-medical workers trained by the World Health Organisation, Leprosy Control Officer in 1966.

Adiza (1971) quoted by Burgoyne (1974) gives a prevalence rate of 20 per thousand and in the same paper Pedley is quoted as giving the lepromatous to non lepromatous rate as $1: 1.4$.

Bhutan, Nepal's eastern neighbour, has been studied for the Leprosy Mission since 1966, by Berkeley and Berkeley (1969). The first prevalence rate of 39.3 per thousand in 5778 persons was modified in a later systematic survey to 13.6 (West Bhutan) and 23.3 (East Bhutan) per thousand. They noted a lepromatous to non-lepromatous rate of $1: 1.6$ and their figures agreed with Seghal (1969) that the age of onset for males was maximal, in five-year groups, between 15 and 30 years i.e. spanning the age group of the majority examined in this survey (17 to 30 years).

The results of the present survey agree more with those of Berkeley and Berkeley (1969) rather than those of Mali (1966, 1969 and 1971), Nepal Health Survey (1966) and Hajini and Shah (1974). The reasons for the apparent discrepancy are that smaller surveys conducted by medical practitioners are more likely to detect lesions and that with smaller numbers complete disrobing is possible.

The other skin conditions noted were consistent with the general incidence noted in hospital dermatological clinics but it is of interest that neither psoriasis nor lichen planus were observed. Buccal and lingual lesions of lichen planus were also absent whereas Pindborg (1972) found 1.5 per cent of 7639 patients in South West India had oral lichen planus, although the clinical and biopsy findings were not correlated with an examination of the skin.

Burgoyne (1974) observed that, in a small survey conducted at several health units in Nepal, tinea cruris and tinea versicolor were frequently seen while tinea pedis was rare, no figures of incidence or prevalence were given and the contrast with the present survey is probably due to differences of clothing, footwear and hygiene. She reported also that psoriasis occurred relatively commonly which was not the case among the Gurkha soldiers but her observations on comedone type of acne and distribution of warts were in keeping with the present findings.

\section{Conclusion}

The survey produced evidence that although a group of soldiers may be selected, as are the Gurkhas, by experienced para-medical recruiting staff and doctors, there remains a possibility of an indeterminate lesion being overlooked and of the later development of leprosy.

In view of the discovery of other treatable abnormalities, hernias, infections etc. in addition to leprosy it is suggested that an annual examination would help to detect 
early disease and thus early treatment; rather than placing reliance on the soldier to report sick or on four-yearly Pulheems examination.

Browne (1970a) quotes Cochrane and Davey (1963):-

"Leprosy often goes unrecognised: Its clinical manifestations are misinterpreted, treated for years with antifungal ointments or labelled hysteria ". "But it can be and should be diagnosed; in most cases all that is required is a little knowledge, observant eyes and a piece of cotton wool ".

Browne (1970b) further states:-

"Many infections fail to establish themselves. Others may become evident as localized skin areas of slight, transient and self-limiting changes in pigmentation, tactile sensitivity, sweating etc. These macules of ' indeterminate' leprosy are single or multiple usually ill defined, non irritating and symptomless, and occur characteristically on the trunk and upper aspects of the limbs ".

"In some countries these indeterminate lesions account for the majority of cases of clinical leprosy. They remain unrecognised unless systematic and regular population surveys are undertaken ".

These statements from authorities on leprosy show that early diagnosis of leprosy is not easy but every Service Medical Officer, like the civilian practitioner, dealing with a non-white population should maintain a high index of suspicion to avoid the consequence of untreated disease.

\section{REFERENCES}

AdizA, R. B. (1971). Incidence of leprosy detection (quoted by Burgoyne 1974). J. Nepal med. Ass. 10, 295.

BeRKeley, J. S. and Berkeley, M. I. K. (1970). Preliminary report on leprosy in Bhutan. Int. J. Leprosy $38,78-82$.

Browne, S. G. (1970a). Therapeutic and clinical leprosy. Brit. J. Hosp. Med. 4, 441-448.

Browne, S. G. (1970b). Leprosy. Documenta Geigy Acta Clinica 11. J. R. Geigy SA, Basle, Switzerland. Browne, S. G. (1973). The epidemiology of leprosy. Z. Tropenmed. Parasit. 24, (suppl.) 1-8.

BurgoYné, J. S. (1974). Dermatology in Nepal. Int. J. Derm. 13, 104-106.

Cochrane, R. G. and Davey, T. F. (1963). Eds. Leprosy in Theory and Practice. Wright. Bristol.

HaIIN, G. H. and ShaH, S. N. A. (1974). Prevalence of leprosy in Kashmir. Indian J. Derm. Venereol. 40, 159-161.

MALI, I. B. (1966). Leprosy survey and control pilot project. H.M.G./Nepal. J. Nepal med. Ass. 4, 330-338.

MALI, I. B. (1969). Leprosy in Nepal. J. Nepal med, Ass. 9, 31-36.

MALI, I. B. (1971). Leprosy in Nepalese children. J. Nepal med. Ass. 9, 207-208.

Nepal Health Survey (1965-1966). Chapter 6. Diseases Transmitted by Direct Contact, University of Hawaii Press. Honolulu.

Pedley, J. C. (1974). Personal communication quoted by Burgoyne (1974).

Pindborg, J. J., Tali, S., Mehta, D. K., Daftary, P. C. and Bhonsle, R. B. (1972). Prevalence of oral lichen planus among 7639 Indian villagers in Kerala, South India. Acta derm.-venereol (Stockh.) 52, 216-220.

RIDLEY, D. S. and Jopling, W. H. (1966). Classification of leprosy according to immunity. A five-group system. Int. J. Leprosy 34, 255-273.

Scutt, R. and Gotch, C. (1974). Skin Deep. The Mystery of Tattooing. Peter Davies Ltd. London.

Seghal, V. N. (1970). A study of age at onset of leprosy. Int. J. Derm. 9, 196-199. 